\title{
Dynamic Relationships in the Australian Labour Market: Heterogeneity and State Dependence*
}

\author{
Stephen Knights \\ Balliol College \\ Oxford, UK \\ Mark Harris and Joanne Loundes \\ Melbourne Institute of Applied Economic and Social Research \\ The University of Melbourne
}

Melbourne Institute Working Paper No. 6/00

ISSN 1328-4991

ISBN 0734014864

May 2000

\begin{abstract}
In this study, individual labour market dynamics are analysed using the Australian Longitudinal Survey. A random utility framework for analysing discrete choices is adopted. In this context, a model incorporating a state dependent relationship between employment outcomes is estimated. The influence on individual employment outcomes of additional variables including education, gender and unemployment benefits is also investigated. It is found that, even after controlling for observable and unobservable differences between individuals, there is strong evidence of state dependence. In certain key respects, the findings of this study differ markedly from those of other Australian labour market studies. It is expected that these findings will provide further insight into the causes of contemporary unemployment, and may constitute further evidence of a 'scarring' effect of unemployment.
\end{abstract}

Melbourne Institute of Applied Economic and Social Research

The University of Melbourne, Victoria 3010 Australia

Telephone (03) 83445330

Fax (03) 83445630

Email melb.inst@iaesr.unimelb.edu.au

WWW Address http://www.ecom.unimelb.edu.au/iaesrwww/home.html 


\section{Introduction}

It is important to know at an individual level whether "state dependence" drives employment prospects, or conversely, is it "heterogeneity"? Namely, is the cause of the relative disadvantage of an unemployed worker the mere experience of being unemployed (state dependence), or alternatively can it be attributed to observed or unobserved individual heterogeneity.

On this issue, disagreement exists in the literature. For example, Phelps (1972) argues that true state dependence exists. By contrast, Cripps and Tarling (1974) argue that what appears to be state dependence is, in fact, "spurious" state dependence due to unobserved heterogeneity. Although the issue of state dependence vs heterogeneity has been broached in several international studies (see for example Flaig et al (1993), Heckman (1981c), Hyslop (1999), Muhleisen and Zimmerman (1994)), we are unaware of any body of research investigating state dependence in Australian employment data. The major contribution of this study is to investigate whether such dynamic relationships exist in the Australian labour market (specifically, the youth labour market).

To assess the validity of these competing explanations, it is necessary to define a dynamic model of unemployment; econometrically, it should include a lagged dependent variable as a regressor. Moreover, theoretical arguments have been put forward to justify the existence of dynamic relationships within labour markets. If the event of being unemployed leads to a slowdown, or even a reversal, in the growth of human capital, an individual's chances of again finding employment would progressively worsen (Heckman, 1981a). This would be theoretically consistent with state dependence. Alternatively, if employers face asymmetrically inferior information about individuals' respective marginal revenue products, they may use past unemployment records as a screening device. Again, this could account for such observed behaviour. Finally, if individuals' time horizons are shortened by past spells of unemployment, they may systematically substitute away from present consumption towards leisure, implying that their opportunity cost of being unemployed would fall (Hotz et al (1988)). This, too, would be consistent with state dependence.

These theoretical arguments all share the feature that they support an explicit dynamic process where individuals' employment prospects change over time. However, they are also consistent with purely static explanations for unemployment which imply that individuals differ in their employment prospects. Most notable among these are the insider-outsider hypotheses advanced by Layard \& Nickell (1986) and Lindbeck \& Snower (1986), where the labour force is modelled as being partitioned according 
to whether one is in employment or not.

The potential policy implications of the existence of dynamic relationships are important. A typical goal of policy making is to increase employment incidence within disadvantaged groups in the labour force. However, effectively attaining such a goal depends upon recognising distinctions such as the above, which relate to the causes - and thus composition - of unemployment. If employment outcomes are strongly state dependent, future policies which increase aggregate employment may have very different impacts between cohorts of workers, depending on the existing employment incidence within each cohort. Under such circumstances, it is quite likely that the benefits of greater employment will be concentrated disproportionately among those already employed, to the exclusion (and further disadvantage) of those currently unemployed. Therefore, if the goal of policy-makers is to increase employment among disadvantaged groups, merely increasing the amount of employment opportunities may not be sufficient.

The structure of the study is as follows. Section 2 surveys the characteristics of dynamic models of unemployment, paying particular attention to differences between, and similarities within, the contemporary literature. Section 3 develops a simple model of state-dependence within a random utility equilibrium framework. To test the model, an appropriate estimation procedure, making use of numeric maximum likelihood estimation techniques, is justified in Section 4. Section 5 describes the data used for the empirical work, and discusses the results. The final section presents several conclusions.

\section{Background}

The techniques used in the literature to model state dependence are highly influenced by whether the dynamics are modelled in discrete or continuous time. If one is interested in modelling the incidence (as opposed to the duration) of unemployment, then discrete-time modelling is accomplished by using binary variables to denote employment/unemployment outcomes. This approach is typified in Arulampalam (1998) and Flaig et al (1993). For an overview of these and other modelling strategies, see Lancaster (1990, Ch.3).

Many of the empirical models rely exclusively on cross-sectional data, where individuals are not identified over time. This was particularly prevalent in earlier models (Heckman \& Borjas (1980), Miller (1989), Narendranathan et al (1985)), and generally owed less to theoretical or empirical advantages, than to the greater ease with 
which such data could be obtained. ${ }^{1}$ A very small proportion of models use pure time series data. ${ }^{2}$ However, a consensus has emerged in favour of - wherever possible - utilizing the greater flexibility and informational content of longitudinal (panel) data. A key advantage of such data is that it allows the researcher to adequately control for unobservable individual heterogeneity, and truly test the hypothesis of state dependence $v s$ heterogeneity ${ }^{3}$. Examples of longitudinal analyses of state dependence may be found in Flaig et al (1993) and Muhleisen \& Zimmermann (1994). However, no previous studies have tested for state dependence using Australian data, although a number of studies have modelled duration dependence. ${ }^{4}$

\section{Modelling Unemployment}

\subsection{Theoretical Model}

On the supply side, individuals make optimal decisions to allocate available time between work and leisure. ${ }^{5}$ Individuals may also have access to some sort of financial endowment, which may either be unrelated to the work-leisure decision (such as existing wealth), or alternatively may be contingent to some extent upon it (such as unemployment benefits). In the presence of wage rates which are low relative to prices of goods and services, it may be optimal for individuals to allocate no time for work. Therefore, each individual may be said to have a certain 'reservation' wage. If wages fall below reservation wages, employment will not be chosen.

The determinants and functional form of utility, will potentially vary - perhaps widely - across individuals; therefore, a need for caution exists when compiling a list of variables which may determine utility, and hence affect reservation wages. However, past studies have indicated that characteristics such as education, marital status and level of past indebtedness acquired broadly influence work-leisure choices across society. ${ }^{6}$ In accordance with existing knowledge of the relationship between age/experience and the incidence of unemployment (see for example Miller, 1989), the

\footnotetext{
${ }^{1}$ Relative to, in particular, longitudinal models which were then comparatively scarce.

${ }^{2}$ For example, Jackman \& Layard (1990), when modelling duration dependence.

${ }^{3}$ Heckman (1981b, p.92) uses the term spurious state dependence to denote the erroneous labelling as state dependence of what is, in fact, unobservable heterogeneity. The issue is further discussed in Section 3.1 below.

${ }^{4}$ See, for example, Stromback et al (1998), Aungles \& Stewart (1986), Brooks \& Volker (1985) and Hui (1985).

${ }^{5}$ It should be noted that 'work' in this context is a simplification, which includes both time spent in actual employment, and time spent searching for employment when a job cannot instantly be found. A substantial literature on the latter exists: for a useful economic and econometric overview of search theory (Zaretsky \& Coughlin (1995)).

${ }^{6}$ See, for example, Bureau of Labour Market Research (1986).
} 
experience variable for males was entered in exponential form, such that experience $=\exp (-0.1 *$ experience $)$, where experience is proxied by age minus the year the individual left school. Due to this parameterization, a negative relationship between age and employment is expected. A slightly different method was used to calculate female potential experience, as they are more likely to suffer from interupted spells in the labour force due to the presence of children. This was done by weighting experience (age minus year left school) by the number of children present. As no exponential was taken, the relationship between experience and employment is expected to be positive for females. Labour market theory also suggests that, at least in the medium run, any regional imbalances in unemployment rates - up to the cost of inter-regional migration differentials - will be erased. However, it is quite possible that in the short run one's place of abode will affect employment prospects. Place of residence may also affect the intensity of job search.

On the demand side, firms make hiring decisions generally based on maximising profits. This problem's optimal solution involves hiring only workers whose estimated marginal revenue products are at least as high as their respective wage rates. ${ }^{7}$ Assuming that each worker's individual marginal product does not vary across hours of employment, the firm will decide whether to hire or not purely on the basis of this criterion.

Simultaneously solving demand and supply will theoretically lead to the establishment of an equilibrium wage for each worker. However, such an approach is likely to prove empirically intractable, due to identification issues. ${ }^{8}$ For example, education may increase an individual's expectations of high remuneration and thus their reservation wage (supply-side) while simultaneously increasing their marginal revenue product (demand-side). In such circumstances, where it is impossible to observationally distinguish supply factors from demand factors, the structural system is said to be under-identified, and individual demand and supply equations cannot be separately estimated. ${ }^{9}$ Nevertheless, to avoid the unrealistic assumption of ignoring demand

\footnotetext{
${ }^{7}$ The qualification that marginal revenue products need to be estimated is important where firms cannot verify these characteristics with certainty. In particular, where such information is assymetrically held (known to the worker but not the firm), a strategic situation arises, in which firms may need to consciously hire less than the 'optimal' number of workers (Shapiro and Stiglitz (1984)).

${ }^{8}$ Heuristically, the problem is that changes in equilibrium wage rates could be generated either by shifts in demand or supply. If explanatory variables are correlated with both demand and supply, then such shifts cannot be, empirically, distinguished from each other. For a general discussion of identification issues, see Johnston (1984, pp.452-460).

${ }^{9}$ One way to separately estimate supply and demand equations is to obtain explicit data on individual's reservation wages. Recent work along these lines has been completed, in an Australian context, by Heath \& Swann (1999).
} 
side issues, there are several variables that can be incorporated which may potentially affect an individual's attractiveness to an employer. These include education, nationality/racial origin, age, physical ability and gender. Labour market participants may be unfairly disadvantaged according to nationality/racial origin, physical ability and gender. Human capital, as proxied by age and educational attainment, is likely to be viewed as a favourable trait by potential employers.

To avoid the likely under-identification problems inherent in structurally modelling labour demand and supply separately, employment outcomes are assumed to be equilibrium values, and a set of variables which may explain these outcomes is constructed. No attempt is made to further classify any of these variables as belonging, exclusively, to either the supply or demand side of the labour market.

Therefore, in lieu of individually estimating demand and supply equations, a probabilistic approach is used, following Flaig et al (1993) to model employment outcomes. An individual's employment status ("employed" or "unemployed") is simply modelled as a binary variable, the result of an underlying latent index. This index can be viewed as the excess of wage offers for individual $i$ in time period $t\left(w_{i t}\right)$, to their contemporaneous reservation wages, $w_{i t}^{*}$ thus

$$
y_{i t}^{*}=w_{i t}-w_{i t}^{*}, i=1, \ldots, N, t=1, \ldots, T \text {. }
$$

Moreover, this index is likely to be a function of observed characteristics (as well as macroeconomic variables) $x_{i t}$, with unknown weights $\beta$, such that

$$
y_{i t}^{*}=x_{i t}^{\prime} \beta+v_{i t}
$$

where $v_{i t}$ is the usual disturbance term, assumed to be normally distributed with zero mean and scalar variance $\sigma_{v}^{2}$. However, we are unlike to observe the difference $w_{i t}-w_{i t}^{*}$ for each individual. What is observed is the realisation of $y_{i t}$, such that the individual is employed if $y_{i t}^{*}$ is positive and unemployed otherwise. Thus

$$
y_{i t}= \begin{cases}1 & \text { if } w_{i t}-w_{i t}^{*} \geq 0 \\ 0 & \text { if } w_{i t}-w_{i t}^{*}<0\end{cases}
$$

where unity denotes employed and zero unemployed. ${ }^{10}$

\subsection{Empirical Model and State Dependence vs Heterogene- ity}

To allow for unobserved heterogeneity, we follow the usual procedure (see, for example Butler and Moffitt (1982) and Hsiao (1986)) in decomposing $v_{i t}$ into an time-invariant

\footnotetext{
${ }^{10}$ There is no focus in this paper on individuals who are not in the workforce.
} 
individual effect $\varepsilon_{i}$, and a time- and individual- varying component $\eta_{i t}$,

$$
v_{i t}=\varepsilon_{i}+\eta_{i t}
$$

The $\varepsilon_{i}$ and $\eta_{i t}$ are assumed to follow independent normal distributions with zero mean and respective variances, $\sigma_{\varepsilon}^{2}$, and $\sigma_{\eta}^{2}$ (Butler and Moffitt (1982)). The correlation between composite error terms over time (the intra-class correlation coefficient) is

$$
\rho \equiv \frac{\sigma_{\varepsilon}^{2}}{\sigma_{\varepsilon}^{2}+\sigma_{\eta}^{2}}, t \neq s .
$$

To test the hypothesis of true state dependence, it is necessary to augment the vector of explanatory variables to include the individual's previous employment status, $y_{i, t-1}$. Thus the full model becomes

$$
y_{i t}^{*}=x_{i t}^{\prime} \beta+\delta y_{i, t-1}+\varepsilon_{i}+\eta_{i t}
$$

On the assumption of independent normality and, for identification purposes, normalising $\sigma_{\varepsilon}^{2}$ to unity, the likelihood function for such a panel probit model is (Butler and Moffitt (1982))

$$
\log L=\sum_{i} \log P\left(y_{i}\right)
$$

where:

$$
P\left(y_{i}\right)=\int_{-\infty}^{\infty} \frac{1}{\pi^{1 / 2}} \exp ^{-\tilde{\varepsilon}_{i}^{2}} \prod_{t=1}^{T} \Phi\left[\left(z_{i t}^{\prime} \gamma / \sigma_{\eta}+\tilde{\varepsilon}_{i} \theta\right)\left(2 y_{i t}-1\right)\right] d \tilde{\varepsilon}_{i}
$$

and:

$$
\begin{aligned}
z_{i t} & =\left(x_{i t} \mid y_{i, t-1}\right) \\
\gamma & =\left(\beta^{\prime} \mid \delta\right)^{\prime} \\
\tilde{\varepsilon}_{i} & =\varepsilon_{i} / \sqrt{2} \\
\theta & =[2 \rho /(1-\rho)]^{1 / 2} .
\end{aligned}
$$

The integral in equation (6) has no closed form, and has to be evaluated using Gaussian quadrature, using the Hermite integration formula.

Consistent estimation obtained by maximisation of equation (4), relies on the assumption that all of the explanatory variables are independent of the (composite) disturbance term. Following Chamberlain $(1980,1984)$ we can allow for possible correlations of the individual effects and $x_{i t}$, by including the time average of the time varying variables $\bar{z}_{i}$ as additional explanatory variable. However, this procedure is not suitable for the lagged endogenous variable, in which instance the so-called 
initial conditions problem arises. This problem has been well documented in the literature (see inter alia, Arulampalam, 1998 Flaig et al, 1993, Heckman, 1981a, b and c, and Orme, 1997).

The consequence of the lagged dependent variable in equation (5) is that unless the initial values are truly exogenous, they will be correlated with the individual effect of the same equation. Heckman's (1981b) simplified procedure for dealing with such, involves approximating the latent variable $y_{i 0}^{*}$ by a linear function of relevant pre-sample information $x_{i 0}$ thus

$$
y_{i 0}^{*}=x_{i 0}^{\prime} \beta_{0}+\alpha_{i} .
$$

To allow for a correlation between the individual effects of equations (5) and (7), specify $\alpha_{i}$ is specified as a linear function of $\varepsilon_{i}$ such that

$$
\alpha_{i}=\psi \varepsilon_{i}+\eta_{i 0}
$$

The extent of correlation between $\varepsilon_{i}$ and $\alpha_{i}$ is therefore, by construction, a function of $\psi$

$$
\rho_{\varepsilon \alpha}=\psi \sigma_{\varepsilon} / \sigma_{\alpha}
$$

The vector $x_{i 0}$ is a likely to contain all of the original variables in $x_{i t}$ plus any additional pre-sample information. To undertake full information maximum likelihood estimation, the product of equation (6) is simply augmented by $\Phi\left[\left(x_{i 0}^{\prime} \beta_{0} / \sigma_{\eta_{0}}+\varepsilon_{i} \psi / \sigma_{\eta_{0}}\right)\left(2 y_{i 0}-1\right)\right]$ thus

$$
\begin{aligned}
P\left(y_{i}\right)= & \int_{-\infty}^{\infty} \frac{1}{\pi^{1 / 2}} \exp ^{-\tilde{\varepsilon}_{i}^{2}}\left\{\prod_{t=1}^{T} \Phi\left[\left(z_{i t}^{\prime} \gamma / \sigma_{\eta}+\tilde{\varepsilon}_{i} \theta\right)\left(2 y_{i t}-1\right)\right]\right\} \times \\
& \left\{\Phi\left[\left(x_{i 0}^{\prime} \beta_{0} / \sigma_{\eta_{0}}+\tilde{\varepsilon}_{i} \theta_{0}\right)\left(2 y_{i 0}-1\right)\right]\right\} d \tilde{\varepsilon}_{i}
\end{aligned}
$$

\section{The Data}

The Australian Longitudinal Survey (ALS) has been used extensively in analyses of the Australian labour market, and is an ideal data set for the purposes of this study due to the size of the sample, the range of responses recorded, and the panel nature of the data. ${ }^{11}$ It contains survey responses from almost 9000 individuals, covering a wide range of demographic and labour market characteristics. In this paper, the data used cover the period 1985-1988; initially the data set contained 8998 respondents, which fell to 6151 by 1988 . General descriptions of this data set, which is managed by

\footnotetext{
${ }^{11}$ For a comprehensive bibliography, see the Department of Employment, Education and Training (1990).
} 
the Bureau of Labour Market Research (BLMR), may be found in McRae (1984) and in Harris (1993). The most pertinent study for this paper is that by Harris (1996) who considered a static panel probit model of unemployment, which, by definition, could not address the issue of state dependence versus heterogeneity. Following Harris (1996), the data were subdivided according to education and gender to account for endogenous attrition, yielding four subgroups: high-education males; high-education females; low-education males; and, low-education females. In particular, it was found in Harris (1996) that low-education males and females were more likely to 'deselect' themselves from the ALS than were their high-education counterparts. ${ }^{12}$

Tables 1 and 2 present the sample means of the variables that are used in the estimation for the high-education and low-education groups, respectively. Individuals who have completed at least secondary school are more likely to be employed over the samle period. For the high-education group, males are more likely to have a trade qualification, whereas females are more likely to have completed either year 12 or a diploma. The replacement ratio is higher for women, and for the low-education group. Low-education males are more likely to be single and living at home. Low-education females are more likely to have completed year 11 as compared to low-education males. Males are liss likely to have an employed partner, particularly low-education males.

In terms of the initial conditions variable means, high-education individuals are less likely to have gone to a state school, or to have taken more than six months to find their first job. They are more likely to have been employed at the time of the survey. Males were more likely to have got their first job in the manufacturing industry, especially if they had not completed a secondary education.

For more information about the data used, including definitions of all variables, refer to the Data Appendix of this study.

\section{Estimation Results}

\subsection{High-Education Equations}

Table 3 presents the estimation results, with respect to the employment status equation, for males and females with high levels of education.

The most obvious finding is the significance of the coefficient on the lagged dependent variable, lagged employment. This finding applies irrespective of gender and suggests that, even after controlling for observed and unobserved heterogeneity, past

\footnotetext{
${ }^{12}$ See Harris (1996, p.122).
} 
Table 1: High education Australian born males and females 1985-88 (sample means)

\begin{tabular}{lcccccc}
\hline \hline Variable & \multicolumn{3}{c}{ Male } & \multicolumn{3}{c}{ Female } \\
\cline { 2 - 7 } & Obs. & Mean & Std. Dev. & Obs. & Mean & Std. Dev. \\
\hline Within Sample & & & & & & \\
Lagged employment & 3776 & 0.86 & 0.35 & 2732 & 0.90 & 0.30 \\
Experience & 3776 & 0.53 & 0.13 & 2732 & 5.73 & 2.30 \\
Marital status & 3776 & 0.30 & 0.46 & 2732 & 0.31 & 0.46 \\
Separated & 3776 & 0.01 & 0.10 & 2732 & 0.01 & 0.11 \\
City & 3776 & 0.76 & 0.42 & 2732 & 0.79 & 0.41 \\
Rural & 3776 & 0.07 & 0.26 & 2732 & 0.05 & 0.22 \\
Own house & 3776 & 0.19 & 0.39 & 2732 & 0.17 & 0.38 \\
Rent free & 3776 & 0.14 & 0.35 & 2732 & 0.12 & 0.32 \\
Renting & 3776 & 0.66 & 0.48 & 2732 & 0.69 & 0.46 \\
Year 12 & 3776 & 0.29 & 0.45 & 2732 & 0.33 & 0.47 \\
Degree & 3776 & 0.09 & 0.28 & 2732 & 0.08 & 0.27 \\
Diploma & 3776 & 0.14 & 0.34 & 2732 & 0.44 & 0.50 \\
Trade certificate & 3776 & 0.37 & 0.48 & 2732 & 0.05 & 0.21 \\
Partner's employment & 3776 & 0.20 & 0.40 & 2732 & 0.29 & 0.46 \\
Health status & 3776 & 0.07 & 0.25 & 2732 & 0.07 & 0.26 \\
Children & 3776 & 0.19 & 0.57 & 2732 & 0.08 & 0.36 \\
Average experience & 3776 & 0.53 & 0.12 & 2732 & 5.74 & 2.01 \\
Replacement ratio & 3776 & 0.33 & 0.10 & 2732 & 0.42 & 0.13 \\
\hline Initial Conditions & & & & & & \\
State school & 944 & 0.74 & 0.44 & 683 & 0.72 & 0.45 \\
Manufacturing industry & 944 & 0.13 & 0.34 & 683 & 0.04 & 0.19 \\
Both parents & 944 & 0.90 & 0.30 & 683 & 0.89 & 0.31 \\
Less than 6 months & 944 & 0.32 & 0.47 & 683 & 0.35 & 0.48 \\
Six months & 944 & 0.10 & 0.30 & 683 & 0.15 & 0.35 \\
Employment history & 944 & 0.74 & 0.44 & 683 & 0.70 & 0.46 \\
Unemployment history & 944 & 0.03 & 0.16 & 683 & 0.04 & 0.19 \\
\hline \hline
\end{tabular}


Table 2: Low education Australian born males and females 1985-88 (sample means)

\begin{tabular}{lcccccc}
\hline \hline Variable & \multicolumn{3}{c}{ Male } & \multicolumn{3}{c}{ Female } \\
\cline { 2 - 7 } & Obs. & Mean & Std. Dev. & Obs. & Mean & Std. Dev. \\
\hline Within Sample & & & & & & \\
Lagged employment & 2108 & 0.75 & 0.43 & 1176 & 0.84 & 0.36 \\
Experience & 2108 & 0.57 & 0.16 & 1176 & 5.43 & 2.56 \\
Marital status & 2108 & 0.25 & 0.43 & 1176 & 0.31 & 0.46 \\
Separated & 2108 & 0.01 & 0.12 & 1176 & 0.02 & 0.14 \\
City & 2108 & 0.63 & 0.48 & 1176 & 0.63 & 0.48 \\
Rural & 2108 & 0.12 & 0.32 & 1176 & 0.10 & 0.30 \\
Own house & 2108 & 0.10 & 0.30 & 1176 & 0.15 & 0.36 \\
Rent free & 2108 & 0.16 & 0.37 & 1176 & 0.13 & 0.33 \\
Renting & 2108 & 0.72 & 0.45 & 1176 & 0.70 & 0.46 \\
Year 10 & 2108 & 0.56 & 0.50 & 1176 & 0.50 & 0.50 \\
Year 11 & 2108 & 0.29 & 0.45 & 1176 & 0.39 & 0.49 \\
Partner's employment & 2108 & 0.12 & 0.32 & 1176 & 0.30 & 0.46 \\
Health status & 2108 & 0.10 & 0.30 & 1176 & 0.07 & 0.25 \\
Children & 2108 & 0.21 & 0.59 & 1176 & 0.13 & 0.47 \\
Average experience & 2108 & 0.57 & 0.15 & 1176 & 5.44 & 2.31 \\
Replacement ratio & 2108 & 0.38 & 0.12 & 1176 & 0.49 & 0.15 \\
Initial Conditions & & & & & & \\
\hline State school & 527 & 0.89 & 0.31 & 294 & 0.88 & 0.32 \\
Manufacturing industry & 527 & 0.17 & 0.37 & 294 & 0.09 & 0.28 \\
Both parents & 527 & 0.86 & 0.35 & 294 & 0.86 & 0.35 \\
Less than 6 months & 527 & 0.27 & 0.45 & 294 & 0.30 & 0.46 \\
Six months & 527 & 0.15 & 0.36 & 294 & 0.20 & 0.40 \\
Employment history & 527 & 0.57 & 0.50 & 294 & 0.60 & 0.49 \\
Unemployment history & 527 & 0.09 & 0.28 & 294 & 0.10 & 0.29 \\
\hline \hline
\end{tabular}


Table 3: Within sample: high education Australian born individuals, 1985-88

\begin{tabular}{lllll}
\hline \hline Variable & \multicolumn{3}{c}{ Male } & Female \\
\cline { 2 - 5 } & Coefficient & t-statistic & Coefficient & t-statistic \\
\hline Constant & -1.209 & -1.55 & 0.426 & 0.77 \\
Lagged employment & 0.772 & 4.79 & 0.838 & 4.16 \\
Experience & -0.034 & -0.03 & 0.058 & 0.89 \\
Marital status & -0.011 & -0.05 & 0.269 & 0.94 \\
Separated & $\mathrm{n} / \mathrm{a}^{2}$ & $\mathrm{n} / \mathrm{a}^{2}$ & $\mathrm{n} / \mathrm{a}^{2}$ & $\mathrm{n} / \mathrm{a}^{2}$ \\
City & -0.009 & -0.07 & 0.349 & 2.28 \\
Rural & -0.773 & -4.02 & -0.048 & -0.23 \\
Own house & 0.543 & 1.64 & 0.218 & 0.62 \\
Rent free & 0.014 & 0.04 & -0.477 & -1.29 \\
Renting & 0.684 & 1.94 & 0.068 & 0.19 \\
Year 12 & 0.177 & 0.82 & 0.432 & 2.29 \\
Degree & 0.772 & 2.44 & 0.420 & 1.49 \\
Diploma & 0.301 & 1.38 & 0.235 & 1.28 \\
Trade certificate & 0.123 & 0.68 & -0.240 & -1.01 \\
Partner's employment & 0.008 & 0.50 & -0.081 & -0.27 \\
Health status & -0.236 & -1.14 & -0.379 & -2.12 \\
Children & 0.011 & 0.08 & -0.255 & -1.60 \\
Average experience & 2.438 & 1.82 & -0.014 & -0.20 \\
Replacement ratio & 1.120 & 0.84 & -0.933 & -0.88 \\
\hline \hline
\end{tabular}


employment status significantly predicts present employment outcomes. This suggests the employment prospects of individuals are affected by something intrinsic to the experience of being unemployed.

Each set of results reveals several characteristics that are important in determining individual employment status. However, no variable other than the lagged effect is significant - at a 5\% two-tailed significance level - for both genders at once. In particular, the replacement ratio appears to have no impact on employment prospects for either gender. Neither does marital status, number of children, type of housing arrangement, nor experience.

Educational attainment seems, not surprisingly, to affect employment prospects positively, even within the high-education groups. However, the effect for males was observed only for those with a degree; while for females, the difference lay between those with at least Year 12 and those with only Year 11. This suggests some segmentation by gender, with females more likely to find employment not requiring tertiary education (but requiring Year 12), while males may be less likely to find such employment.

Regional differences also appear significant, but again the effects differ across gender. For males, employment prospects are negatively affected by living outside a city or country town, but no other effects can be detected. Females, by comparison, have significantly lower probabilities of being employed anywhere outside of a city. Again, this suggests labour market segmentation, with males more likely to work in country towns relative to females, but both less likely to find rurally-based employment (relative to city-based employment).

The only variables which significantly affect employment prospects, therefore, are those relating to past employment, education and place of residence (those females who suffer from a disability were also negatively affected). By contrast, Harris (1996) found that age, housing arrangements, marital status and partner's employment status were also significantly correlated with employment status, across gender divisions. These substantially different results suggest that a great deal of correlation attributed to various explanatory variables in the earlier study may be due directly to past differences in employment outcomes across individuals.

Such an interpretation is supported by the results from the auxiliary, Initial Conditions model, given in Table 4. Very few coefficients are significant. Those that are include (for males) experience, although with an incorrect sign; and (for both genders) length of search time for first job, and employment/unemployment history. Since the lagged dependent variable is not explicitly included, it is plausible that these variables - all of which relate to each individual's history - proxy for it in the 
model. Indeed, if this evidence is taken at face value, it is accurate to characterise present outcomes as 'dominated by those of the past, regardless of how the past came about.'

Table 4: Initial conditions: high education Australian born individuals, 1985-88

\begin{tabular}{lllll}
\hline \hline Variable & \multicolumn{3}{c}{ Male } & Female \\
\cline { 2 - 5 } & Coefficient & t-statistic & Coefficient & t-statistic \\
\hline Constant & -1.871 & -1.45 & 0.185 & 0.12 \\
Experience & 2.826 & 3.07 & -0.057 & -0.84 \\
Marital status & 0.103 & 0.24 & -0.745 & -1.19 \\
City & 0.585 & 2.93 & 0.321 & 1.20 \\
Rural & -0.396 & -1.31 & -0.291 & -0.65 \\
Own house & 0.560 & 1.00 & -0.237 & -0.23 \\
Rent free & 0.518 & 0.99 & 0.277 & 0.28 \\
Renting & 0.097 & 0.18 & -0.115 & -0.12 \\
Western origin & -0.119 & -0.14 & 0.469 & 0.48 \\
Year 12 & -0.001 & 0.00 & 0.462 & 1.26 \\
Degree & 0.745 & 1.54 & 0.997 & 1.34 \\
Diploma & 0.499 & 1.24 & 0.601 & 1.60 \\
Trade certificate & -0.067 & -0.22 & 0.409 & 0.70 \\
Partner's employment & -0.494 & -1.14 & 1.323 & 1.44 \\
Health status & -0.158 & -0.63 & -0.313 & -0.94 \\
Children & -0.139 & -0.49 & -0.897 & -2.11 \\
State school & 0.055 & 0.18 & -0.178 & -0.32 \\
Manufacturing industry & -0.898 & -4.20 & -0.848 & -1.60 \\
Both parents & -0.112 & -0.38 & -0.309 & -0.66 \\
Less than 6 months & 1.066 & 2.78 & 1.128 & 3.05 \\
Six months & 0.904 & 2.09 & 1.069 & 2.66 \\
Employment history & 0.423 & 1.73 & 0.039 & 0.14 \\
Unemployment history & -0.214 & -0.44 & -1.069 & -2.63 \\
\hline \hline
\end{tabular}

Of particular interest is the insignificance of the replacement ratio (defined as the ratio of unemployment benefit to the average weekly wage) for both genders, which runs counter to other studies [e.g. Pissarides (1991)]. This finding would appear to suggest that reducing the level of unemployment benefits is unlikely - in itself - to effectively reduce unemployment, as unemployment benefits do not appear to have any significant impact on reservation wages. Theoretically, this may be due to individuals possessing very low reservation wages, so that the level of unemployment benefits is not a binding constraint for their labour force participation decisions. Alternatively, it may reflect the inapplicability of the average wage for capturing labour market choices, since the relevant wage at the marginal hiring level may in 
Figure 1: Probability of unemployment: high education females

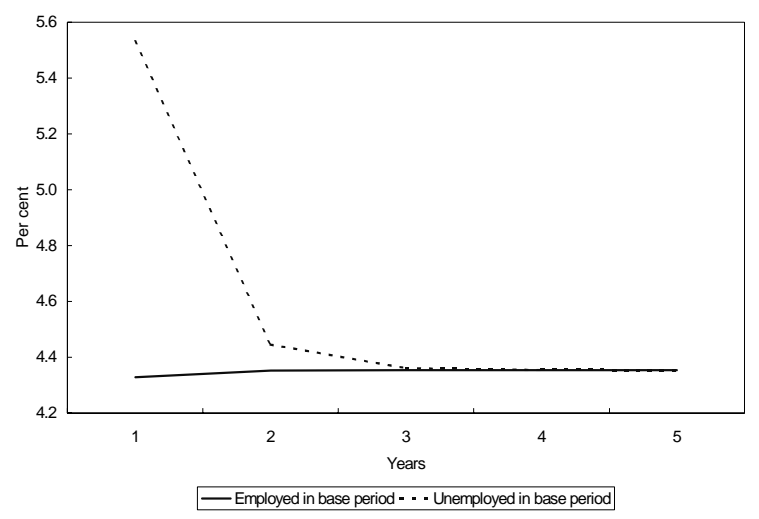

fact be the minimum wage; this explanation has been suggested by Heath and Swann (1999).

Figures 1 and 2 present the probability of being unemployed depending on whether an individual is employed or unemployed in the first period for females and males, respectively. Noteworthy is the apparent 'scarring' effect that being unemployed has on individuals. High-education females that are unemployed in the base period have nearly a 5.6 per cent chance of being unemployed in the first year (evaluating all other characteristics at their sample means). This declines rapidly in the second year, and the effect eventually wears off by the fourth year. As expected, those who are employed in the base period have a lower probability of being unemployed in the first year (around 4.3 per cent), a result that remains fairly stable over time.

High-education males exhibit a similar scarring effect, although the probability of being unemployed is much lower than that for high-education females. The spread between probabilities depending on whether an individual is employed or unemployed in the base period is also substantially narrower than the female results ( 0.6 per cent compared to 1.3 per cent) suggesting that high-education males are unlikely to suffer as much, relative to their employed counterparts.

\subsection{Low-Education Equations}

Table 5 presents the estimation results with respect to the employment status equation, for males and females with low-education.

Similar to the high-education groups, the clearest positive finding was the strong direct correlation between employment outcomes over time, after controlling for observed and unobserved differences between individuals. This effect was significant, at 
Figure 2: Probability of unemployment: high education males

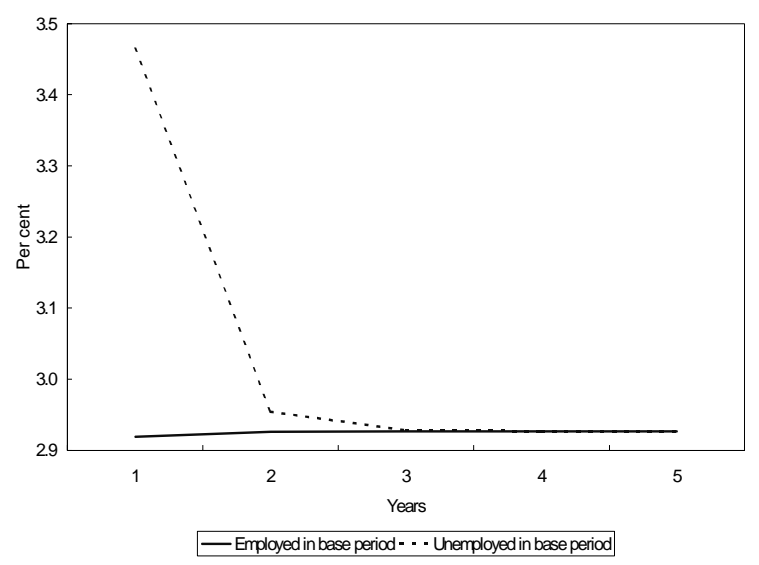

Table 5: Within sample: low education Australian born individuals, 1985-88

\begin{tabular}{lllll}
\hline \hline Variable & \multicolumn{3}{c}{ Male } & Female \\
\cline { 2 - 5 } & Coefficient & t-statistic & Coefficient & t-statistic \\
\hline Constant & -1.143 & -1.33 & -1.282 & -0.92 \\
Lagged employment & 0.512 & 3.22 & 0.903 & 3.02 \\
Experience & -1.839 & -1.40 & 0.138 & 1.27 \\
Marital status & -0.560 & -1.74 & -0.108 & -0.07 \\
Separated & -0.243 & -0.49 & -0.226 & -0.15 \\
City & 0.220 & 1.62 & 0.074 & 0.31 \\
Rural & -0.413 & -1.83 & -0.121 & -0.33 \\
Own house & 0.124 & 0.25 & 1.144 & 0.87 \\
Rent free & -0.800 & -1.68 & -0.055 & -0.04 \\
Renting & -0.020 & -0.04 & 0.806 & 0.65 \\
Year 10 & 0.276 & 1.26 & 0.392 & 1.12 \\
Year 11 & 0.503 & 2.02 & 0.886 & 2.07 \\
Partner's employment & 0.518 & 1.86 & -0.329 & -0.25 \\
Health status & -0.348 & -1.86 & $\mathrm{n} / \mathrm{a}^{2}$ & $\mathrm{n} / \mathrm{a}^{2}$ \\
Children & 0.014 & 0.09 & -0.541 & -1.76 \\
Average experience & 3.839 & 2.45 & -0.092 & -0.76 \\
Replacement ratio & 1.943 & 1.42 & 1.902 & 1.20 \\
\hline \hline
\end{tabular}


a 5\% two-tailed significance level, for both genders.

Educational levels again were significant, even within the low-education groups. The more schooling an individual had attained, the better were their employment prospects. In particular, completion of Year 11 significantly increased the probability of being employed, regardless of gender. However, there were no significant differences in job prospects among those who had completed Year 10 and below.

However, somewhat surprisingly, individual work experience exhibited no significant correlation with employment prospects. For females, neither individual nor group effects of experience were observed. These findings are difficult to interpret; however, it is reasonable to conclude that experience effects on employment prospects are not strong overall within the low-education groups. This applies to both the structural and initial conditions models (Table 6).

Table 6: Initial conditions: low education Australian born individuals, 1985-88

\begin{tabular}{lllll}
\hline \hline Variable & \multicolumn{3}{c}{ Male } & Female \\
\cline { 2 - 5 } & Coefficient & t-statistic & Coefficient & t-statistic \\
\hline Constant & -2.830 & -2.16 & -2.965 & -1.72 \\
Experience & 1.209 & 1.62 & -0.017 & -0.25 \\
Marital status & -0.333 & -0.81 & -0.791 & -0.59 \\
Separated & 0.775 & 0.07 & 0.114 & 0.08 \\
City & 0.115 & 0.52 & 0.249 & 1.00 \\
Rural & -0.265 & -0.83 & 0.403 & 0.92 \\
Own house & 2.529 & 2.69 & 1.006 & 0.95 \\
Rent free & -0.178 & -0.26 & 0.129 & 0.14 \\
Renting & 1.006 & 1.53 & 0.210 & 0.24 \\
Western Origin & 0.041 & 0.05 & 1.292 & 2.25 \\
Year 10 & 0.312 & 1.18 & 0.684 & 1.73 \\
Year 11 & 0.337 & 1.16 & 1.052 & 2.45 \\
Partner's employment & 0.608 & 1.08 & 0.394 & 0.29 \\
Health status & 0.397 & 1.41 & $\mathrm{n} / \mathrm{a}^{2}$ & $\mathrm{n} / \mathrm{a}^{2}$ \\
Children & -0.045 & -0.13 & -0.301 & -0.92 \\
State school & 1.088 & 2.19 & 0.950 & 0.91 \\
Manufacturing industry & -0.488 & -1.97 & -0.393 & -1.01 \\
Both parents & 0.343 & 1.35 & 0.151 & 0.53 \\
Less than 6 months & -0.075 & -0.23 & 0.885 & 2.27 \\
Six months & 0.184 & 0.54 & 0.729 & 1.85 \\
Employment history & 0.731 & 3.33 & 0.223 & 0.72 \\
Unemployment history & -0.441 & -1.51 & -0.696 & -1.84 \\
\hline \hline
\end{tabular}

No other variables exhibited significant correlation with employment prospects. Again, this may be interpreted as evidence that employers and employees place great 
Figure 3: Probability of unemployment: low education females

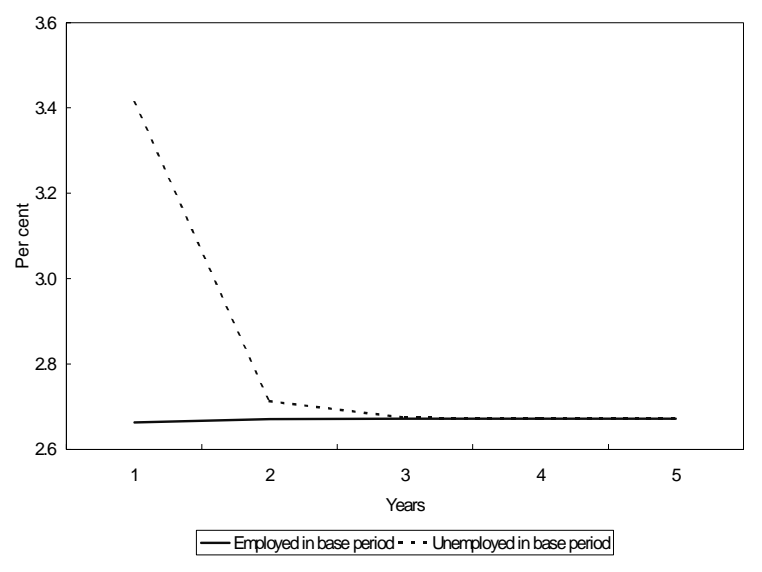

weight on recent employment history in deciding whether to, respectively, hire or offer labour. Another interesting characteristic of the low-education groups is the similarity between males and females; in particular, gender differences are less obvious than are so for the high-education groups.

Harris (1996) found evidence that the probability of being employed was - for both genders of low-education - significantly correlated with age, education, partner's employment status and existence of a disability. In addition, marital status and housing arrangements played a role for males, while females were affected by the number of children. By contrast, this current study's results differ in assigning much lesser roles to many of these variables in explaining employment outcomes. This pattern is broadly similar to the results for the high-education groups.

As with the high-education individuals, figures 3 and 4 present the probability of being unemployed depending on whether an individual is employed or unemployed in the base period. Interestingly, females who have - at most - obtained an education to year 11 are less likely to be unemployed than their more highly educated counterparts. This holds regardless of whether they are employed or unemployed in the base period. A scarring effect is still evident, although the difference in probabilities (between being unemployed or employed in the base period) is only around 0.8 per cent.

Low-education males appear the ones most likely to suffer from a spell of unemployment. There is almost a 9 per cent chance that individuals who are unemployed in the base period will remain so in the subsequent year, although again, this falls dramatically in the second year with the effect wearing off by the fourth year. Nevertheless, once the scarring effect has worn off, the probability of being unemployed at any given time is still quite high (just over 8 per cent). 
Figure 4: Probability of unemployment: low education males

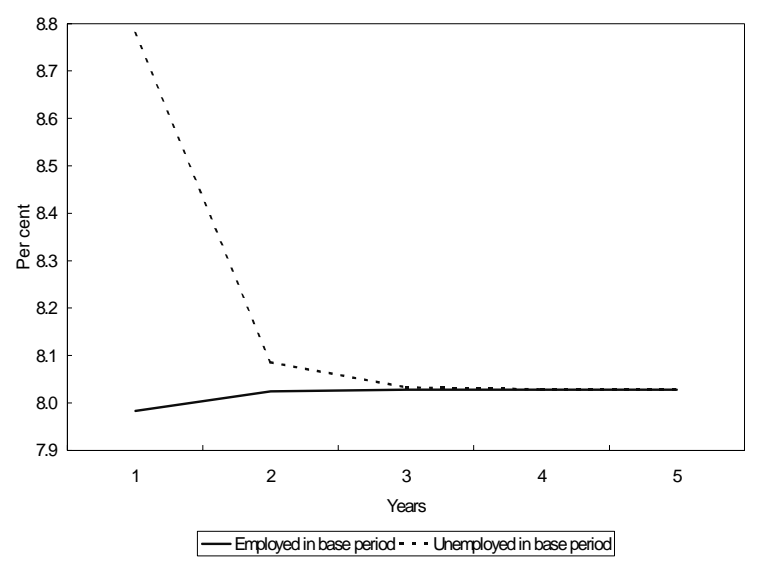

\section{Conclusions}

This study has used a dynamic framework to analyse the incidence of employment outcomes. By including a one-period lagged value of the dependent variable as a regressor, it has been possible to incorporate the effect of employment history on current employment prospects. Importantly, this has been done after controlling for both observed and unobserved differences between individuals, so that true state dependence is measured.

The results of the study indicate that prior employment status, as measured by the respondent's employment status one year ago, significantly predicts current employment outcomes, across education levels and genders. It has also established that inclusion of prior employment status results in other variables, such as labour force experience, housing arrangements and marital status, being afforded a much lesser predictive role than would otherwise have been the case. Results are broadly similar across gender and educational levels, although gender differences are more pronounced for the high-education groups.

From a theoretical perspective, the study examines the issue of state dependence using a supply and demand framework. It is decided that supply and demand influences cannot be easily separated, and urged that only equilibrium outcomes should be modelled in the absence of information necessary to do so. Results lend broad support to insider-outsider hypotheses of the labour market, with some sort of partitioning of the labour market according to prior employment status apparent.

Finally, this study's results should be of particular use to policy-makers in the Australian environment where recent unemployment rates have been more often falling 
than rising. As was pointed out in the introduction, it is not only the overall rate of unemployment which is of concern, but also the composition of unemployment. It appears to be the case that those who become unemployed, for whatever reason, are likely to stay so. Therefore, significant action may be required to prevent unemployment becoming perpetually concentrated within relatively small groups. Such action could plausibly take the form of targeted wage subsidies, to prevent certain groups becoming unemployed in the first instance. Complementary actions could also be taken to attempt to provide advantage to those already unemployed, perhaps through schemes designed to aid formation of human capital. It would be highly desirable for future initiatives to analyse the likely interactions of such policies with the dynamic effects identified here. By so doing, it may be possible to provide an environment where the needs of those most disadvantaged within the labour market may be met. 


\section{Data Appendix}

\section{Descriptions of variables used}

All variables are, either directly or indirectly, from the ALS data set (for specification of the ALS, see McRae (1984)), over the period 1985-1988.

\section{Dependent Variable}

Employment Status

A binary variable was created.

Employment Status $=0$ denotes respondent was unemployed.

Employment Status $=1$ denotes respondent was employed.

Those absent for the full duration of the sample were treated as missing values. Those present for part of the sample had values recorded for those periods and missing values recorded for periods spent outside the labour force. Thus, all individuals who are counted in a given period were either in employment or actively seeking work during that period.

\section{Explanatory Variables: Overall Model}

Constant

Estimated constant term.

Employment Status in previous period

As for Employment Status.

Experience

Defined as period elapsed between time of first entry into labour market and time of current survey. For females, this calculation was subsequently weighted according to number of children (using weights inferred from Harris (1996)).

Marital Status 8 Separated

2 binary variables were created to denote marital status.

The default category (i.e. Marital Status $=$ Separated $=0$ ) denotes single.

Marital Status $=1$ denotes married.

Separated $=1$ denotes separated, divorced, or widowed.

City Dwelling \& Rural Dwelling

2 binary variables were created to denote place of residence.

The default category (i.e. City Dwelling = Rural Dwelling $=0$ ) denotes dwelling in country town.

City Dwelling $=1$ denotes dwelling in city.

Rural Dwelling $=1$ denotes dwelling in rural area which is not a country town.

Buying House $\&$ Renting/Boarding House $\&$ Rent Free House

3 binary variables were created to denote financial commitments related to dwelling. 
The default category (i.e. Buying House $=$ Renting/Boarding House $=$ Rent Free House $=0$ ) denotes ownership of house.

Buying House $=1$ denotes buying house.

Renting House $=1$ denotes renting house or boarding.

Rent Free House $=1$ denotes living in rent free accommodation or already owning house.

Year $10 \&$ Year 11

2 binary variables were created to denote highest level of education for loweducation respondents (i.e. those respondents with a level of education no higher than completion of Year 11)

The default category(i.e. Year $10=$ Year $11=0$ ) denotes lower than completion of Year 10.

Year $10=1$ denotes completion of Year 10 .

Year $11=1$ denotes completion of Year 11 .

Year 12 $\&$ Trade Qualification \& Diploma $\&$ Degree

4 binary variables were created to denote highest level of education for higheducation respondents (i.e. those respondents with a level of education no lower than completion of Year 11).

The default category (i.e. Year $12=$ Trade Qualification $=$ Diploma $=$ Degree $=$ 0 ) denotes completion of other qualification.

Year $12=1$ denotes completion of Year 12 .

Trade Qualification $=1$ denotes completion of trade qualification.

Diploma $=1$ denotes completion of diploma or certificate from TAFE or business college.

Degree $=1$ denotes completion of degree.

Partner's Employment Status

As for Employment Status. The binary variable was only recorded for respondents with Marital Status=1, with missing values recorded for other respondents.

\section{Health Status}

A binary variable (Health Status $=0$ denotes no disability) was created.

Health Status $=1$ denotes respondent disabled insofar as to limit the amount or type of work they could perform.

Number of Children

Defined as respondent's number of children.

Average Experience

Defined as the arithmetic mean of the variable Experience for the respondent's (gender and education) subgroup. 


\section{Replacement Ratio}

Defined as the ratio $\frac{\text { Unemployment benefits }}{\text { Average weekly wage }}, i=1, \ldots, 4$

$i=1$ : high-education females

$i=2$ : high-education males

$i=3$ : low-education females

$i=4$ : low-education males

\section{Explanatory Variables: Initial Conditions Model}

Constant

As for overall model.

Experience

As for overall model.

Marital Status \& Separated

As for overall model.

City Dwelling \& Rural Dwelling

As for overall model.

Buying House 8 Renting or Boarding House $\&$ Rent Free House

As for overall model.

Year 10 \& Year 11

As for overall model.

Year 12 \& Trade Qualification \& Diploma 8 Degree

As for overall model.

Partner's Employment Status

As for overall model.

Health Status

As for overall model.

Number of Children

As for overall model.

Western origin

A binary variable was created.

Western $=1$ denotes of western racial origin.

Western $=0$ denotes of aboriginal, Asian, or other non-western racial origin.

State school

A binary variable was created.

State School $=0$ denotes attendance at state or catholic school.

State School $=1$ denotes attendance at other type of school.

Manufacturing industry

A binary variable was created. 
Manufacturing Industry $=1$ denotes first job was in manufacturing industry.

Both parents

A binary variable was created.

Both parents $=1$ denotes both parents were present at age 14 .

Less than six months $\&$ Six months

2 binary variables were created to denote length of search time before finding first job.

The default category (i.e. Less than six months $=$ Six months $=0$ ) denotes length of search time before finding first job was less than two weeks.

Less than six months $=1$ denotes length of search time before finding first job was between 2 weeks and six months.

Six months $=1$ denotes length of search time before finding first job was more than six months.

\section{Employment History \& Unemployment History}

2 binary variables were created to denote the respondent's employment status at survey times.

The default category (i.e. Employment history $=$ Unemployment history $=0$ ) denotes respondent was employed in as many surveys as unemployed.

Employment history $=1$ denotes respondent was employed in more surveys than unemployed.

Unemployment history $=1$ denotes respondent was unemployed in more surveys than employed. 


\section{References}

[1] Arulampalam, W. (1998), "State Dependence in Unemployment Incidence: Evidence for British Men 1991 - 1995”, Seventh Biennial International Conference on Panel Data, June 1998, Gothenburg, Sweden.

[2] Aungles, P. and Stewart, B.P. (1986), "The Duration of Unemployment of CES Registered Job-seekers: An Econometric Analysis", Bureau of Labour Market Research Working Paper No. 66.

[3] Brooks, C. and Volker, P. (1985), "The Influence of Unemployment Duration and Heterogeneity on the Transition from Unemployment for Australian Youth", Bureau of Labour Market Research Working Paper No. 55.

[4] Bureau of Labour Market Research (1986), "The First Wave of the ALS: Facts and Figures about Young CES Registrants", Monograph Series No. 15, Bureau of Labour Market Research, Canberra: AGPS.

[5] Butler, J.S. and Moffitt, R. (1982), "A Computationally Efficient Quadrature Procedure for the One Factor Multinomial Probit Model", Econometrica, 50, pp.761-764.

[6] Chamberlain, G. (1984), "Panel Data", in Handbook of Econometrics, (eds. S. Griliches and M. Intrilligator), Amsterdam: North-Holland, pp. 1247-1318.

[7] Chamberlain, G. (1985), "Heterogeneity, Omitted Variable Bias, and Duration Dependence", in Longitudinal Analysis of Labor Market Data, (eds. J. J. Heckman and B. Singer), pp. 3-38, New York: Cambridge University Press.

[8] Cripps, T, and Tarling, R. (1974), "An Analysis of the Duration of Male Unemployment in Great Britain, 1932-1973", Economic Journal, 84, pp. 289-316.

[9] Department of Employment, Education and Training (1990), Australian Longitudinal Survey, 1985-1988: A Research Bibliography, Canberra: AGPS.

[10] Flaig, G., Licht, G. and Steiner, V. (1993), "Testing for State Dependence Effects in a Dynamic Model of Male Unemployment Behaviour", in Panel Data and Labour Market Dynamics, (eds. H. Bunzel, P. Jensen and N. Westergard-Neilsen), pp.189-213, North Holland, Amsterdam: Elsevier Science Publishers.

[11] Greene, W. (1997), Econometric Analysis, $3^{\text {rd }}$ edition, New Jersey: PrenticeHall. 
[12] Harris, M.N. (1993), "The Australian Longitudinal Survey: A Reference Document", memo, Department of Econometrics, Monash University.

[13] Harris, M.N. (1996), "Modelling the Probability of Youth Unemployment in Australia", Economic Record, 72, pp. 118-129.

[14] Heath, A and Swann, T. (1999), "Reservation Wages and the Duration of Unemployment", Reserve Bank of Australia Research Discussion Paper 1999-02.

[15] Heckman, J. J. (1981a), "Statistical Models for Discrete Panel Data", in Structural Analysis of Discrete Data with Econometric Applications, (eds. C. F. Manski and D. McFadden), pp. 196-217, Cambridge: MIT Press.

[16] Heckman, J. J. (1981b), "The Incidental Parameters Problem and the Problem of Initial Conditions in Estimating a Discrete Time-Discrete Data Stochastic Process", in Structural Analysis of Discrete Data with Econometric Applications, (eds. C. F. Manski and D. McFadden), pp. 179-195, Cambridge: MIT Press.

[17] Heckman, J. J. (1981c), "Heterogeneity and State Dependence", in Studies in Labor Markets, (ed. S. Rosen), pp.91-139, Chicago: University of Chicago Press.

[18] Heckman, J. J. and Borjas, G. J. (1980), "Does Unemployment Cause Future Unemployment? Definitions, Questions and Answers from a Continuous Time Model of Heterogeneity and State Dependence", Economica, 47, pp. 247-283.

[19] Hotz, V. J., Kydland, F. E. and Sedlacek, G. L. (1988), "Intertemporal Preferences and Labor Supply", Econometrica, 56, pp. 335-360.

[20] Hsiao, C. (1986), Analysis of Panel Data, Cambridge, UK: Cambridge University Press.

[21] Hui, W. (1986), "State Dependence and Youth Unemployment in Australia: A Survival Analysis", ANU Working Papers in Economics and Econometrics No. 138.

[22] Hyslop, D. R. (1999), "State Dependence, Serial Correlation and Heterogeneity in Intertemporal Labor Force Participation of Married Women", Econometrica, 67, pp.1255-1294.

[23] Jackman, R. and Layard, R. (1990), "Does Long-term Unemployment Reduce a Person's Chance of a Job? A Time-series Test", Economica, 58, pp.93-106.

[24] Johnston, J. (1984), Econometric Methods, 3rd edition, New York: McGraw-Hill. 
[25] Lancaster, T. (1990), The Econometric Analysis of Transition Data, Cambridge, UK: Cambridge University Press.

[26] Layard, R. and Nickell, S. J. (1986) "The Causes of British Unemployment", National Institute Economic Review, 0, pp. 62-85.

[27] Lindbeck, A. and Snower, D. (1986), "Wage Setting, Unemployment and InsiderOutsider Relations", American Economic Review, 76, pp. 235-239.

[28] McRae, I. (1984), "The Australian Longitudinal Survey", BLMR Conference Paper No. 44, Canberra: AGPS.

[29] Miller, P.W. (1989), "The Structure of Aboriginal and Non-Aboriginal Youth Unemployment", Australian Economic Papers, 28(52).

[30] Muhleisen, M. and Zimmermann, K. F. (1994), "A Panel Analysis of Job Changes and Unemployment", European Economic Review, 38(3-4), pp. 793-801.

[31] Narendranathan, W., Nickell, S. and Stern, J. (1985), "Unemployment Benefits Revisited", Economic Journal, 95, pp.307-Phelps, E. (1972), Inflation Policy and Unemployment Theory: The Cost Benefit Approach to Monetary Planning, London: Macmillan.

[32] Olsen, C. (1996), "Unemployment Duration in the United States: An Application of a Competing Risks Model", Master of Commerce Research Report, University of Melbourne, unpublished.

[33] Orme, C. (1997), The Initial Conditions Problem and Two-Step Estimation in Discrete Panel data Models, mimeo, University of Manchester.

[34] Phelps, E. (1972), Inflation Policy and Unemployment Theory: The Cost Benefit Approach to Monetary Planning, London: Macmillan.

[35] Pissarides, C. (1991), "Real Wages and Unemployment in Australia", Economica, $58(1)$, pp. 35-55.

[36] Shapiro, C. and Stiglitz, J. E. (1984), "Equilibrium Unemployment as a Worker Discipline Device", American Economic Review, 74(3), pp. 433-444.

[37] Stromback, T., Dockery, M., and Ying, W. (1998), "Transitions in the Labour Market: Evidence from the Survey of Employment and Unemployment Patterns", Melbourne Institute Working Paper Series No. 1/98. 
[38] Trivedi, P. K. and Alexander, J. N. (1988), "Incorporating International Competitiveness into the demand for Labour Function: Some Issues of Specification and Interpretation", Economic Record, 64(186), pp.196-208.

[39] Zaretsky, A. M. and Coughlin, C. C. (1955), "An Introduction to the Theory and Estimation of a Job-Search Model", Federal Reserve Bank of St-Louis Review, 77(1), pp. 53-65. 